\title{
Fatores determinantes para as reduzidas taxas de crescimento do BUSINESS-TO- BUSINESS e uma investigação sobre o tema nas indústrias de Campina Grande
}

Fábio de Oliveira Lucena, MEng

Faculdade de Ciências Sociais Aplicadas (FACISA)

Raniere dos Santos da Silva

Administração (UFRN)

Pesquisas sobre o Business-to-Business (transações eletrônicas entre empresas ou B2B) estimaram que seu uso poderia crescer vertiginosamente ano a ano. Todavia, a despeito de sua sistemática implantação em muitas companhias grandes e seus significativos benefícios, a implementação do B2B não alcançou os esperados níveis quando o setor industrial como um todo é considerado. Este artigo, portanto, procura analisar os fatores que determinaram a não utilização maciça do B2B e apresenta os resultados de uma pesquisa acerca do tema nas indústrias de Campina Grande.

Palavras-chave: reduzido uso do b2b; indústrias campinenses; canal de suprimentos

Researches about Business-to-Business (electronic transactions among companies or B2B) foresaw that its use would grow up quickly year-by-year. However, in spite of its systematic implantation in most of big companies and its significant benefits, the Business-to-Business' implementation didn't reach the expected levels when the all industry segment is considered. This paper intends to analyze the factors that determined the no-utilization in a large scale of the B2B and presents the results of a research about this theme in Campina Grande's industries.

Keywords: reduced use of B2B; campinense industry; supply chain

\section{Introdução}

Diante dos crescentes desafios impostos pelo mercado, torna-se premente a necessidade de ações que concorram para o incremento do grau de competitividade das organizações. E um dos aspectos fundamentais nesse processo de ajustamento estratégico à nova conjuntura econômica refere-se à idéia de focar as atividades da empresa em seus objetivos de produção propriamente ditos, o que implica na redução de investimentos nas atividades meios do processo.

Uma das atividades meio de vital importância ao processo produtivo é o suprimento externo, que segundo Lucena \& Severiano Filho (2002), consiste nas atividades de programação de materiais, rastreamento de preços, relacionamento com os fornecedores, processo efetivo de compras e controle do material recebido, ou seja, aquelas atividades de suprimentos que se encontram à montante do processo produtivo.

Dentre as ações que permeiam o suprimento externo, o processo de compras integrado com fornecedores por meios eletrônicos constitui uma das grandes tendências atuais. E é neste tipo de relação que está inserido o conceito denominado Business-to-Business, ou B2B. Este é fundamentado no intenso uso de tecnologias de comunicação e na profusa troca de informações entre as empresas envolvidas. Desta forma, inúmeras operações (compra, venda, requisição de material, informações 
sobre níveis de estoque etc.) podem ser otimizadas usando-se, por exemplo, a Internet e o EDI Eletronic Data Interchange.

As vantagens competitivas obtidas através do B2B foram, em geral, enormes para as organizações que o adotaram. Naturalmente, faz-se necessária prévia e detalhada análise dos potenciais e das reais necessidades da própria empresa, bem como das de seus fornecedores e clientes.

Embaladas pela grande e repentina explosão verificada há alguns anos com relação aos números do mercado B2B no mundo, muitas foram as previsões divulgadas acerca do vertiginoso crescimento esperado do nível de utilização do Business-to-Business. Com muita facilidade, falava-se em milhões, bilhões até trilhões quando o assunto era o B2B e suas perspectivas para o futuro.

Entretanto, inúmeras pesquisas nacionais e internacionais demostraram que tais previsões eram, na verdade, otimistas demais. Este artigo almeja apresentar (1) os prováveis fatores que fizeram com que as previsões demasiadamente otimistas não se confirmassem e (2) o resultado de uma pesquisa realizada nas indústrias da cidade de Campina Grande/PB sobre o tema. A referida pesquisa vem exatamente corroborar este novo panorama: o B2B continua sendo uma tendência, mas seus níveis de crescimento são bem menores que os alardeados algum tempo atrás.

\section{Suprimento Externo e Comércio Eletrônico}

Convém inicialmente estabelecer alguns conceitos concernentes ao suprimento externo e ao comércio eletrônico, sobretudo o B2B, que é uma das modalidades desse tipo de negócio.

\subsection{Suprimento Externo}

A função compras é um segmento essencial do departamento de materiais ou suprimentos. Para Dias (1993), tem por objetivo suprir as necessidades de materiais ou serviços, planejá-las quantitativamente e satisfazê-las no momento certo com as quantidades corretas, bem como verificar se recebeu efetivamente o que foi comprado e providenciar o armazenamento. Nesta abordagem, o termo compras compreende uma gama maior de atividades, além do próprio ato de compra.

Em termos de definição conceitual, a função compras, consoante Reis (1978), consiste na aquisição de materiais, componentes, produtos e suprimentos necessários à operação do subsistema de produção. A gestão de compras e suprimentos, na visão de Slack et al. (1997), é um termo bem aceito na prática empresarial para designar a função que lida com a interface da unidade produtiva e seus mercados fornecedores.

Em termos de macro-classificações do sistema de suprimento, Lucena \& Severiano filho (op. cit.) esclarecem que este pode configurar-se em dois sub-sistemas distintos. O primeiro pode ser denominado de suprimento externo, uma vez que há uma predominância de atividades e/ou operações explicitamente situadas à montante do processo produtivo, tais como:

- atividades de programação de compras;

- operações de rastreamento de preços;

- atividades de relacionamento com os fornecedores,

- operações de compras propriamente ditas;

- operações de controle de material recebido.

Estas atividades de suprimento externo podem ser visualizadas na Figura 1. 


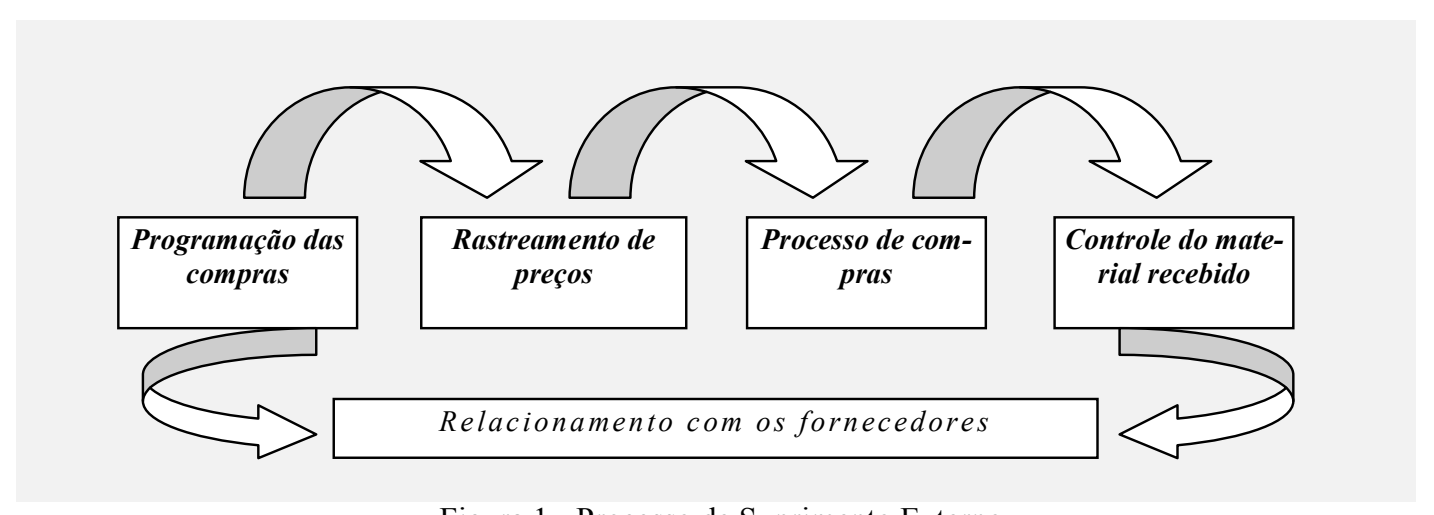

Figura 1 - Processo de Suprimento Externo

Fonte: Lucena \& Severiano Filho (2002)

O processo convencional de suprimento externo se inicia com a demanda por insumos, e a conseqüente programação de compras. $\mathrm{O}$ rastreamento de preços é efetivado com base em fornecedores cadastrados ou não. Uma vez definido o fornecedor, segundo outros critérios além do preço, é formalizado o ato de compra propriamente dito. A entrega do material é acompanhada (follow-up) e recebida na empresa, a qual passa a controlar o material. $\mathrm{O}$ relacionamento com os fornecedores se estabelece desde a procura por materiais e desenvolve-se num processo de avaliação, de negociação de compra e prossegue na entrega do material.

O segundo subsistema, por sua vez, refere-se ao gerenciamento do material no chão-de-fábrica, com o fim de suprir os materiais nos postos de trabalho, no momento e quantidade certos, podendo ser denominado de suprimento interno. As atividades alocadas a este subsistema abrangem o transporte interno de materiais e produtos, bem como os estoques intermediários, traduzindo-se assim como a função responsável pelo fluxo logístico no interior da planta produtiva.

Seja utilizando recursos de pessoal, de máquinas, instalações e equipamentos, as funções do Departamento de Compras são essenciais ao sistema logístico da empresa. Nesta perspectiva, Harding (1981) descreve as funções de compras como sendo as seguintes:

- Avaliação de fornecedores alternativos e o uso de um pequeno, porém eficiente, número de fornecedores para os mais importantes materiais e produtos;

- Habilidade para se comprar a preços competitivos, dando a devida atenção ao custo total a longo prazo, em vez de considerar preço em dado período;

- Avaliação e cadastramento dos fornecedores quanto à entrega, serviço e qualidade, bem como quanto ao preço;

- Engrandecimento da reputação da companhia aos olhos dos fornecedores e dos concorrentes no mercado local;

- Habilidade para ajudar na seleção de novos materiais, devida a uma constante comunicação com o mercado;

- Manutenção adequada dos níveis de estoque por toda a companhia, em conjunto com outros departamentos.

As colocações acima conduzem à percepção de que uma das principais atividades no suprimento externo é justamente a forma como a empresa interage com os seus fornecedores, ou seja, o relacionamento com os mesmos.

Nessa linha de raciocínio, Arnold (1999) sustenta que, no ambiente de negócios da atualidade, o tipo de relação entre fornecedor e comprador é crucial para ambos. Do ponto de vista ideal, a relação será baseada numa dependência mútua e duradoura. $\mathrm{O}$ fornecedor pode confiar em negócios futuros, e $\mathrm{o}$ comprador terá garantia de fornecimento de produtos de qualidade, apoio técnico e ambiente de produto. A comunicação entre comprador e fornecedor deve ser aberta e plena, de modo que ambas as 
partes entendam o problema uma da outra e possa trabalhar juntas na solução de problemas, fato que beneficiará ambas. Assim, a seleção do fornecedor e a relação com ele estabelecida são de

fundamental importância. A justificação dos fornecedores no desempenho do comprador se dá a partir de dois aspectos básicos, apresentados por Isatto \& Formoso (1997):

- O desempenho de seus produtos influencia diretamente o desempenho dos produtos finais da empresa compradora, por meio de atributos como qualidade e custo;

- Os sistemas de gestão empresarial e da produção da empresa compradora criam uma série de exigências para os fornecedores, os quais têm correspondência indireta com os produtos finais da primeira.

Para uma maior compreensão dos tipos de relações com os fornecedores, Mallmann (1995), comentando as observações de Helper ${ }^{1}$, afirma que existem duas dimensões importantes no estabelecimento de relações de suprimento: a troca de informações e o comprometimento existente entre as empresas. A Figura 2 apresenta alguns tipos possíveis de relações de suprimento.

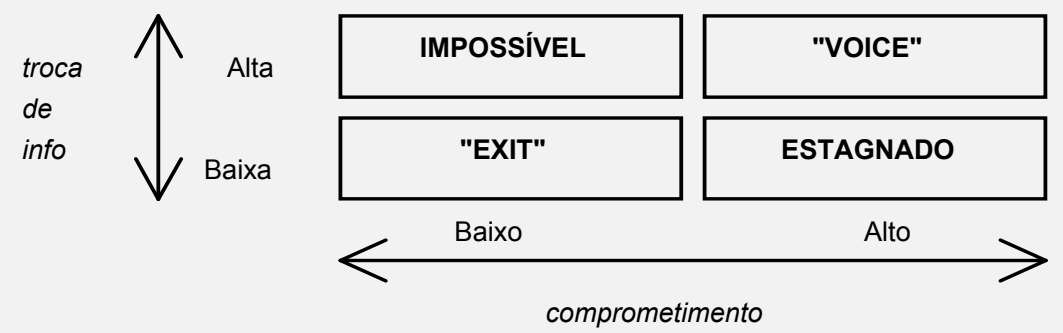

Figura 2 - Tipos Possíveis de Relações de Suprimento Fonte: Adaptado de Mallmann(1995)

Nas relações do tipo "exit", tanto o comprometimento como a troca de informações são baixas. A troca de informações muitas vezes restringe-se apenas ao preço. Nestas relações, o conflito é resolvido, simplesmente, pela troca do fornecedor. A relação caracterizada por um alto comprometimento e baixa troca de informações é uma relação estagnada, pois, não havendo troca de informações, não pode haver sinergia, e não havendo sinergia, não existe potencial de melhoria.

A relação caracterizada por uma alta troca de informações, sem que haja grande comprometimento, é uma relação impossível, pois nenhuma empresa correria o risco, nem assumiria os custos associados à grande troca de informações, sem que houvesse grande comprometimento. O tipo de relação defendido por Helper ${ }^{2}$ como o mais promissor é a relação do tipo "Voice", na qual existe ao mesmo tempo grande troca de informações e grande comprometimento. A esse respeito, Davis, Aquilano \& Chase (2001) consideram alguns elementos no relacionamento adequado com os fornecedores:

- Confiança - um ingrediente fundamental no estabelecimento de relações bem sucedidas entre o fornecedor e o cliente é o elemento confiança. A confiança permite que os fornecedores contribuam para o ciclo de desenvolvimento de novos produtos;

- Relações de longo prazo - com os fornecedores assumindo um papel estratégico numa empresa, é necessário desenvolver relações de longo prazo que permitam que uma visão

\footnotetext{
${ }^{1}$ HELPER, Susan. "How much has really changed between US automakers and their suppliers". Sloan management review. Summer, 1991.

${ }^{2}$ HELPER, Susan. "How much has really changed between US automakers and their suppliers”. Sloan management review. Summer, 1991.
} 
estratégica seja compartilhada. O termo apropriado para o estabelecimento destas relações é, freqüentemente, denominado de contratos perenes, que implicam a renovação automática de contratos com os fornecedores, desde que o desempenho dos mesmos esteja de acordo com o contratado;

- Compartilhamento de informações - o gerenciamento bem sucedido da cadeia de suprimentos envolve o compartilhamento de informações entre fornecedores e clientes. Essas informações podem incluir questões desde as especificações de projeto de novos produtos, até o planejamento e a programação de capacidade, ou o acesso a uma base de dados completa do cliente;

- Forças individuais da organização - se uma empresa inicia uma relação de longo prazo com um fornecedor, então passa a ser importante para ela que esse fornecedor permaneça no mercado por um longo período de tempo. Destarte, um bom cliente trabalhará com seu fornecedor para garantir que este seja lucrativo e continue forte financeiramente.

Em face das considerações acima, viabilizar o estreitamento dos laços entre as empresas e seus fornecedores, através de práticas avançadas, como o B2B, constitui um significativo incremento estratégico para o canal de suprimentos.

\subsection{O Comércio Eletrônico e o B2B}

Segundo Albertin (2000), o comércio eletrônico (CE) é a realização de toda a cadeia de valor dos processos de negócio num ambiente eletrônico, por meio do emprego intenso das tecnologias de comunicação e informação, atendendo aos objetivos de negócio. Para o citado autor, esses processos podem ser efetivados de forma completa ou parcial, incluindo as transações negócio-a-negócio (Business-to-Business ou B2B), negócio-a-consumidor (Business-to-Consumer ou B2C) e intraorganizacional, numa estrutura predominantemente pública e de baixo custo.

A respeito da questão, Cameron, apud Albertin (2000) define que CE inclui qualquer negócio transacionado eletronicamente, em que essas transações ocorrem entre dois parceiros de negócio ou entre um negócio e seus clientes.

O comércio eletrônico, conforme entendimento das Nações Unidas, ocorre quando as transações ou negócios são feitos eletronicamente. Isso inclui a participação de várias formas de informações de negócios trocadas por meios eletrônicos, tais como: mensagens ou cartas eletrônicas, tecnologia World Wide Web, cartões de crédito, transferências eletrônicas de fundos, electronic data interchange etc., entre fornecedores, consumidores, agências governamentais e outros que fazem transações de compra e venda, consumo e atividades administrativas (FELLENSTEIN \& WOOD: 2000).

KalakotA \& Whinston, apud Albertin (op. cit.), consideram que, dependendo do destinatário da pergunta, CE pode ter definições distintas, podendo-se citar as seguintes:

- De uma perspectiva de comunicações, o CE é a entrega de informações, produtos/serviços, ou pagamentos por meio de linhas de telefone, redes de computadores ou qualquer outro meio eletrônico;

- De uma perspectiva de processo de negócio, o CE é a aplicação de tecnologia para a automação de transações de negócio e fluxos de dados;

- De uma perspectiva de serviço, o CE é uma ferramenta que endereça o desejo das empresas, consumidores e gerência para cortar custos de serviços, enquanto melhora a qualidade das mercadorias e aumenta a velocidade da entrega do serviço;

- De uma perspectiva on-line, o CE provê a capacidade de comprar e vender produtos e informações na Internet e em outros serviços on-line.

A Figura 3 apresenta um modelo de comércio eletrônico numa perspectiva integrada, segundo Bloch, Pigneur \& Segev, citados por ALBERTIN (op. cit.). O modelo demonstra que o CE pode ser utilizado 
em todas as fases de uma transação comercial, por meio de uma perspectiva comprador-vendedor e utilizando um modelo de ciclo de vida.

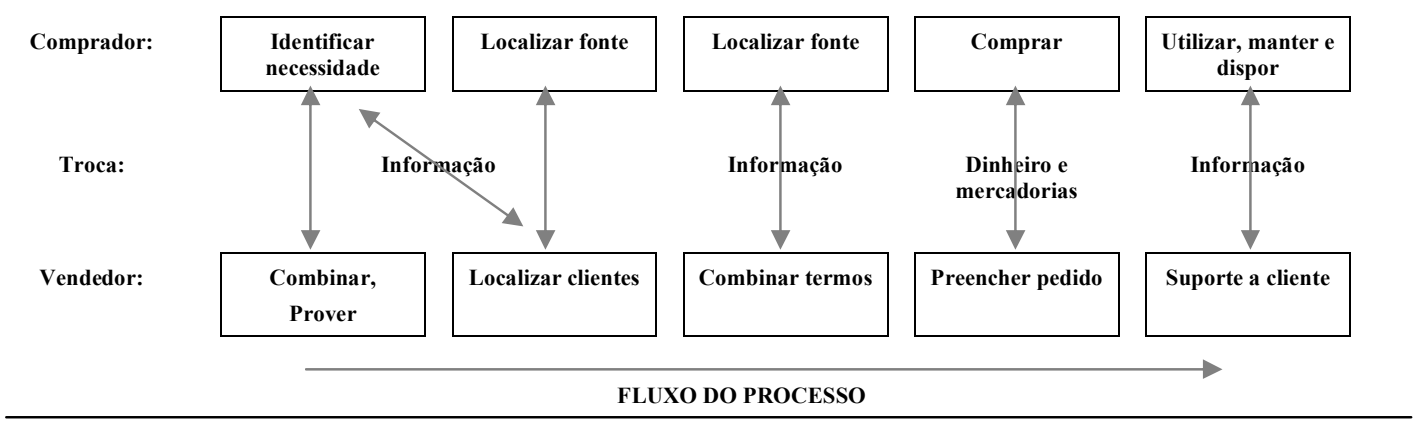

Figura 3 - Modelo de Comércio Eletrônico (Perspectiva Integrada)

Fonte: Adaptado de Bloch, Pigneur \& Segev, apud Albertin (op. cit.)

Entre as manifestações do comércio eletrônico, o B2B assume uma importância, em face das novas configurações que estão se estabelecendo no relacionamento entre empresas.

A esse respeito e consoante Mcgee \& Prusak (1994), existem dois pré-requisitos para se estabelecer o comércio eletrônico:

- O primeiro é criar conexões eletrônicas entre as organizações, correspondendo à infraestrutura digital. Esse aspecto é a parte mais fácil do comércio eletrônico;

- O segundo pré-requisito corresponde ao fluxo eletrônico de dados entre as organizações de uma forma compreensível, ou seja, é preciso que haja regras claras, sem ambigüidades, para interpretação e manuseio dos dados eletrônicos recebidos. Nos Estados Unidos, na Europa e no Japão, a abordagem a esse aspecto tem sido estabelecer padrões que definam equivalentes eletrônicos das formas comerciais que transmitem a maioria das informações entre as empresas hoje em dia, como, por exemplo, pedidos de compra, faturas, cartas de crédito, conhecimento de embarque etc.

Os autores acima consideram que o comércio eletrônico impõe a reengenharia de processos internos e que parte do pensamento voltado para o processo resulta da atenção especial dirigida aos clientes de um determinado processo.

A abordagem de processo, na verdade, leva a uma visão mais ampla das estruturas e atividades organizacionais tradicionais. No contexto inter-organizacional, o pensamento processual chama a atenção para a continuidade dos processos através das fronteiras funcionais tradicionais. Ao invés de pensar em termos de compra e venda, o pensamento processual sugere a caracterização da interação entre as organizações, como "a gestão do processo de reabastecimento", como ilustra a Figura 4. Assim como o pensamento processual é capaz de identificar atividades duplicadas entre funções dentro da organização, o pensamento processual aplicado ao comércio eletrônico pode sugerir oportunidades em que seja questionada a duplicação de atividades entre organizações. 


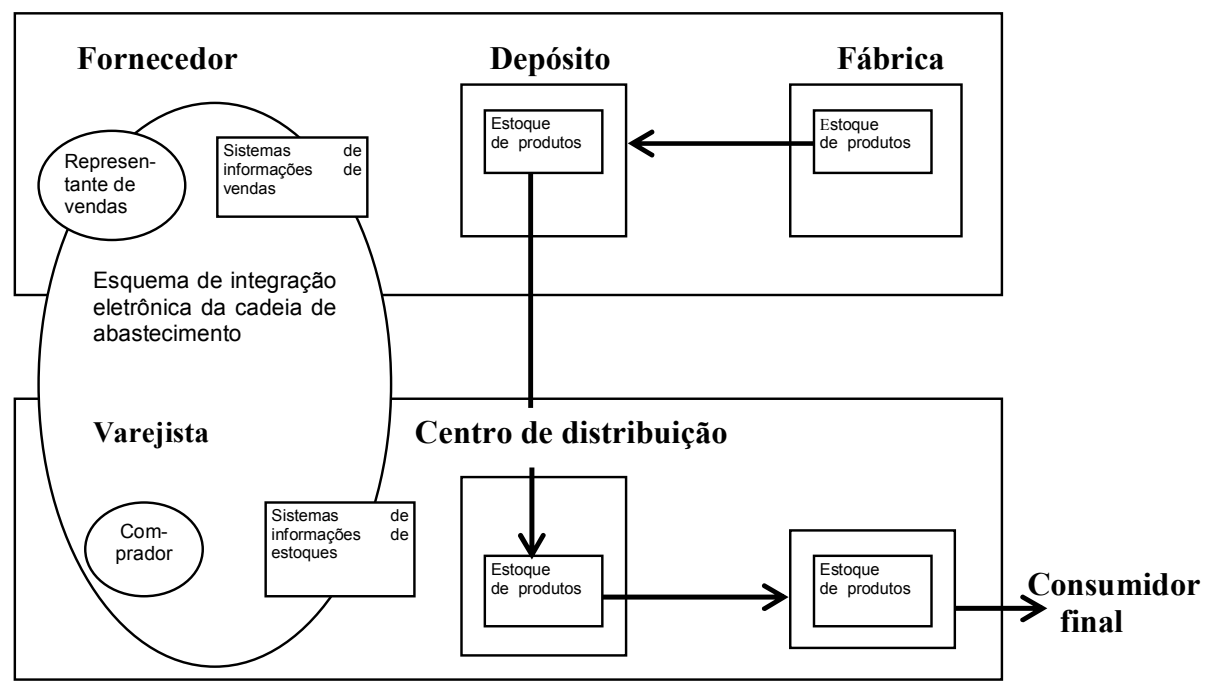

Figura 4 - Administrando o Processo de Reabastecimento Fonte: Adaptado de Mcgee \& Prusak (1994)

É necessário um grande salto conceitual para que a visão do comércio eletrônico seja totalmente percebida. As organizações devem se tornar muito mais conscientes e abertas às dimensões cooperativas da busca de vantagem competitiva.

Conforme Andreotti (2003), o comércio pela Internet já se consagrou - pelo menos nas organizações que atuam na ponta da cadeia de relacionamento - como um canal alternativo de venda ao consumidor final, caracterizando-se pela facilidade e conveniência de compra, por descontos e campanhas promocionais atraentes e apresentando-se como uma forma barata de aumentar a exposição e o alcance das vendas das empresas.

Entretanto, já com relação ao B2B, o caminho parece um pouco mais árduo, pois tal mudança de paradigma parece envolver um número maior de variáveis (confiança mútua, compartilhamento de custos etc.). E na busca pela maximização das chances de sucesso no processo de integração da cadeia, um dos grandes desafios é, segundo Keese (2003), avaliar cuidadosa e adequadamente as características e a influência de cada organização ao longo da cadeia, desde o fornecedor de matériaprima até o consumidor final, já que os impactos das ações de um determinado agente se distribuem aos demais em um "efeito dominó".

\subsection{O B2B e o Suprimento Externo}

Consoante Arnold (1999), as empresas gastam cerca de 50\% de sua renda proveniente das vendas na compra de matérias-primas, componentes e suprimentos. O suprimento externo, portanto, se constitui como um dos elementos mais importantes do processo produtivo, o que determina o enorme potencial da função compras em aumentar os lucros da empresa. Essa percepção é também notada por Dias \& Costa (2000), que consideram o desempenho da área de compras bem estruturada como fator positivo à empresa, independente da importância relativa que a área de compras assume na vida da organização.

É inegável o avanço dos números relativos ao crescimento do volume de transações on-line nos últimos anos no Brasil e no mundo. De fato, é cada vez maior o número de organizações que se utilizam dos meios eletrônicos para se relacionarem com seus clientes e fornecedores, visando a melhores e mais eficiente níveis de integração de suas cadeias de valor. Com este intuito, segundo Lima (2003), inúmeras empresas de grande porte espalhadas pelo mundo têm investido vultosos recursos financeiros, tecnológicos e de pessoal na implantação de sistemas de ERP (Enterprise 
Resources Planning) e aplicações SCM (Supply chain Management) e CRM (Customer Relationship Management). E mais: tamanha é a amplitude de funcionalidades de tais ferramentas que muitas destas empresas já as consideram indispensáveis aos seus negócios.

Em particular, a área de suprimento externo tem sido uma das mais amplamente atingidas dentro das empresas que apelam para os negócios virtuais. Isso se deve ao fato de que, entre outros fatores, de acordo com um estudo da PRICEWATER HOUSE COOPERS apud Persona (2000), um processo convencional de compra entre empresas, que levava em média 7,3 dias, hoje leva apenas dois dias pela Internet. Além disso, o custo médio por pedido caiu de 107 para 30 dólares. $\mathrm{O}$ estudo aponta ainda uma redução de 5 a $10 \%$ nos preços dos produtos, e de 25 a $30 \%$ nos custos de estoque, em face da agilização dos processos de compra.

Para Felipini (2002), a SABESP, empresa de saneamento de São Paulo, é um bom exemplo de organização que vem obtendo excelentes resultados com o B2B. Em seu site, a empresa cadastra os fornecedores que têm interesse em participar das compras, disponibilizando o chamado leilão reverso (processo através do qual os fornecedores fazem lances e vence quem oferecer o menor preço). O site traz também informações sobre, pagamentos, contratos, licitações em andamento etc., oferecendo ainda prêmios para os fornecedores que se destacam pela excelência no fornecimento. Resultado de tudo isso: aumento da eficiência e diminuição de custos.

Segundo Persona (op. cit.), além dos benefícios econômicos relatados, a agilidade na comunicação melhorou o relacionamento entre empresas, permitindo o desenvolvimento de fornecedores estratégicos. Outras vantagens do comércio eletrônico que foram observadas são:

- integração do processo de compras com os sistemas ERP existentes na empresa;

- eliminação de erros (algo comum na transcrição manual de pedidos) em virtude da automatização;

- facilidade no rastreamento e controle de pedidos, propiciando correções de curso em tempo hábil para evitar caros setups das linhas de produção.

A adoção do Business-to-Business permite o processamento de diversas atividades geradoras de custos elevados pelo processo convencional, a saber:

- programação de materiais, com previsão de necessidades futuras;

- cotação de preços;

- informações sobre o plano de produção, que resultem na gestão de suprimento externo;

- ordem de compra;

- acompanhamento de entregas (follow-up);

- comunicação de embarque;

- aceite de materiais entregues.

Observa-se, diante dessas considerações, que o uso eletrônico no processo de suprimento externo viabiliza benefícios consideráveis para as empresas compradoras, como também para os fornecedores, o que fortalece a cadeia de suprimentos (supply chain).

Nessa linha de raciocínio, Merli (1994) afirma que a lógica do relacionamento com os fornecedores integrados, além de elementos, como o relacionamento a longo prazo e confiança recíproca, condiciona também a necessidade de uma rede de informação comum, utilizada tanto para procedimentos operacionais como também para funções administrativas. Mas isso só é possível mediante o processamento de informações on-line - característica fundamental do B2B.

Verifica-se, portanto, que o CE na gestão do SCM constitui uma ferramenta altamente eficaz. Sua adoção possibilita uma significativa redução nos custos com o suprimento externo, liberando capital 
para ser utilizado nas atividades produtivas propriamente ditas. Faz-se necessária, entretanto, uma compreensão adequada das empresas que o aplicam, no intuito de maximizar seus benefícios.

\section{Baixa Utilização do B2B Apesar dos Benefícios no Suprimento Externo}

Apesar de todos os fatores positivos elencados no uso do B2B para o sistema de suprimento externo das empresas, observa-se um crescimento bem mais tímido do que o esperado em relação aos níveis de utilização do B2B nas empresas do Brasil e do mundo.

Com o intuito de traçar um perfil realista da utilização do B2B no Brasil, a Fundação Getúlio Vargas$\mathrm{RJ}$ realizou uma pesquisa em um universo de 310 empresas, das quais cerca $60 \%$ pertenciam ao ranking das 500 maiores do país. Os resultados desta pesquisa, recém-divulgados pela instituição, foram relativos ao ano de 2001 (D’ANGELO, 2002).

Segundo os seus resultados, o número de transações realizadas entre empresas cresceu apenas $0,77 \%$ em relação ao ano de 2000. E mais: o valor atualmente transacionado no comércio B2B brasileiro representa, aproximadamente, apenas $1,18 \%$ do valor do mercado total do negócio-a-negócio, mercado este cujo valor total é estimado em $\mathrm{R} \$ 1,6$ bilhões.

Outro dado obtido foi que a média de crescimento do volume de investimentos das empresas em tecnologia B2B foi da ordem de $0,27 \%$ para a indústria, $0,49 \%$ no comércio e $1,05 \%$ nos serviços.

Uma outra pesquisa, também realizada pela FGV, aponta que apesar de $96 \%$ das médias e grandes empresas possuírem página na Internet, apenas $16 \%$ a usam para a efetiva troca de informações entre elas e seus fornecedores e somente $5 \%$ a usam como ferramenta de realização de transações comerciais (D'ANGELO, 2002).

E em todo o mundo, os números são semelhantes. Mas, como explicar tal fato? Será que o B2B está fadado a ser mais um breve modismo que tende a desaparecer? Mas, e o que dizer de suas comprovadas vantagens competitivas?

\subsection{Fatores Determinantes no Reduzido Crescimento das Taxas de Utilização do B2B}

Romiti (2002) coloca que há cerca de dois anos, nos congressos internacionais e no mercado em geral, os estudiosos do comércio se dividiam, basicamente, em duas grandes correntes. Os "alarmistas" anunciavam o irreversível fim das transações tradicionais entre empresas. Tudo passaria, brevemente, a ser on-line. Já os "fundamentalistas" afirmavam que o B2B se tratava de uma "onda" que duraria 2 ou 3 anos e que, sem consistência, seria esquecida pelas companhias.

Em face das posições extremistas acima, ambos os grupos estavam fadados ao equívoco.

Se por um lado, os "alarmistas" hoje concordam que nem sempre o B2B é a solução mais indicada para a integração entre os elos da cadeia de suprimentos, por outro, os "fundamentalistas" admitem que ela veio para ficar e realmente pode ser bastante útil em muitos casos. $\mathrm{O}$ fato é que, atualmente, a tese dominante no mercado é que as duas formas de comércio vão continuar coexistindo, no mínimo, por muito tempo ainda.

Mas, ideologias à parte, por que o B2B, que já registrou um crescimento estupendo nos primeiros anos, apresenta uma taxa de crescimento tão tímida atualmente?

Inicialmente, deve-se mencionar o fato de que há cerca de quatro anos, "Business-to-Business" era, indiscutivelmente, o tema de maior destaque nas corporações ao redor do mundo sob o aspecto tecnológico, conforme assinala Romiti (2002). Ele era sinônimo de modernidade e eficiência. 
Diante deste cenário, todas as grandes organizações mundiais rapidamente procuraram se adaptar a este novo e irreversível panorama. Por conta disto, os anos que se seguiram foram marcados pelo acelerado crescimento do volume de investimentos no setor patrocinados pelas grandes empresas.

Com o passar do tempo, à medida que todas (ou praticamente todas) as grandes companhias já haviam aderido ao B2B, era chegada a hora de as médias e pequenas darem seqüência à expansão. Entretanto, como seria de esperar, o ritmo verificado foi bem menos frenético, já que todas as empresas remanescentes, de menor porte e com menos capital para investimentos desta natureza, necessitavam de mais tempo e estrutura para se adaptar.

Além do aspecto acima, podem ser enumerados alguns outros fatores que contribuíram para o arrefecimento da expansão do B2B no mundo:

- A implantação de tecnologia B2B requer, necessariamente, um estreitamento nos relacionamentos entre empresas e fornecedores. Um alto nível de confiabilidade e comprometimento na cadeia é condição sine qua non para uma implementação exitosa do sistema, requerendo, portanto uma relação do tipo Voice, como defende Helper ${ }^{3}$ nas considerações do tópico 2.1. Entretanto, na maioria das vezes, os elos do suply chain ainda são muito frágeis, o que acaba por inviabilizar a implantação do B2B;

- Caso uma dada empresa decida aderir ao B2B e tenha todos os requisitos técnicos e financeiros para tanto, ela sozinha não tem como levar o projeto adiante. Até mesmo por motivações conceituais, esta empresa precisa saber se seus fornecedores também têm interesse e condições de participar da implementação do sistema;

- O alto custo ainda é um fator que dificulta a implementação de um sistema B2B. Ainda é muito caro para a maioria das empresas empregar capital com projetos de tecnologia;

- Como se trata de uma verdadeira revolução na forma de trabalhar das empresas, não apenas sob o ponto de vista tecnológico, mas principalmente sob o aspecto cultural, muitas delas ainda não estão preparadas culturalmente para tal guinada. A visão processual colocada por MCGEE \& PRUSAK (op. cit.) seria fundamental nessa transformação da cultura organizacional das empresas envolvidas na cadeia de suprimentos;

- No caso específico do Brasil, um país sem muita tradição tecnológica, muitas empresas ainda se mostram receosas em relação à implantação de novas tecnologias em seu dia-a-dia.

Nessa linha de raciocínio, Chapinotte (2002) assevera que a não utilização ampla do B2B decorre da falta de preparação dos seus back offices, ou seja, grande parte das indústrias continua utilizando processos logísticos obsoletos, confirmando as considerações acima.

\section{A pesquisa nas Indústrias Campinenses}

A pesquisa cujos resultados serão relatados a seguir teve por objetivo verificar o atual estágio do B2B nas indústrias campinenses e, em particular, do emprego do Business-to-Business nas atividades ligadas à cadeia de suprimentos das organizações. Ela foi financiada pelo Conselho Nacional de Desenvolvimento Científico e Tecnológico (CNPq) através do Programa Institucional de Bolsas de Iniciação Científica (PIBIC), sob a supervisão da Universidade Estadual da Paraíba.

\subsection{Universo e Amostra}

O universo da pesquisa foi composto pelas pequenas, médias e grandes indústrias instaladas na cidade de Campina Grande $(\mathrm{Pb})$. Na definição desse universo foi utilizado como critério o número de empregados, conforme a classificação do SEBRAE, apresentada na Tabela 1.

\footnotetext{
${ }^{3}$ HELPER, Susan. "How much has really changed between US automakers and their suppliers". Sloan management review. Summer, 1991.
} 
Tabela 1 - Classificação das organizações industriais, segundo o número de empregados

\begin{tabular}{c|c}
\hline CLASSIFICAÇÃO (PORTE) & NÚMERO DE EMPREGADOS \\
\hline MICROEMPRESA & 01 a 19 \\
\hline PEQUENA EMPRESA & 20 a 99 \\
\hline MÉDIA EMPRESA & 100 a 499 \\
\hline GRANDE EMPRESA & Acima de 500 \\
\hline
\end{tabular}

Fonte: SEBRAE/PB - UNIDADE CAMPINA GRANDE

A partir dos valores da Tabela 1, foi obtida junto à Federação das Indústrias do Estado da Paraíba (FIEP) uma listagem das empresas com 20 (vinte) ou mais funcionários instaladas na cidade de Campina Grande/PB. Esta listagem constituiu o universo inicial da pesquisa e continha exatamente 40 (quarenta) empresas.

Destas 40 indústrias, 4 (quatro) haviam falido, 1 (uma) havia transferido sua produção para a cidade de João Pessoa/PB e 1(uma) não foi localizada. Desta forma, apenas as 34 (trinta e quatro) restantes foram efetivamente visitadas, ou seja, $85 \%$ do universo inicial. Todavia, 8 (oito) destas indústrias não se mostraram acessíveis à pesquisa. As alegações mais comuns para que isso ocorresse foram a falta de tempo e/ou de interesse no assunto.

Desta forma, finalmente, apenas 26 (vinte e seis) indústrias foram objeto da pesquisa. Destas 26 empresas, 16 eram de pequeno porte, 9 de médio e apenas 1 de grande porte. Este número representou $65 \%$ do universo inicial da pesquisa.

\subsection{Resultados}

O estudo foi realizado através da aplicação de entrevistas estruturadas, bem como através da observação sistemática nas empresas constituintes da amostra. Basicamente, as informações coletadas foram divididas em duas categorias (informações preliminares e informações acerca da utilização do B2B nas atividades de suprimento externo).

\subsubsection{Informações Preliminares}

Neste primeiro bloco foram coletadas informações gerais a respeito de cada uma das indústrias pesquisadas (razão social, CNPJ etc.). Em particular, 2 (duas) informações merecem destaque: a quantidade de funcionários e o ramo de atividade da cada empresa.

Comparando os dados obtidos junto à FIEP (dados relativos a 1997) com aqueles coletados através do questionário, constatou-se que a maioria das indústrias reduziu seu quadro de funcionários. Ao todo, 16 empresas dispensaram mão-de-obra (a redução média ficou em torno de 50\%). Por outro lado, outras oito indústrias elevaram sua oferta de trabalho (o aumento médio ficou em torno de $28 \%$ ). Das duas empresas restantes, uma não apresentou alteração na quantidade de funcionários e a outra não pôde ser analisada segundo este aspecto, por ainda não estar em funcionamento no ano de 1997.

Analisadas em seu conjunto, as 26 empresas têm apenas 77,4\% dos funcionários que tinham há 4 (quatro) anos e empregam atualmente 3.933 pessoas.

Outro aspecto que merece destaque é a enorme diversidade observada quanto aos ramos de atividades das empresas pesquisadas. Constatou-se que o parque industrial campinense é bastante diversificado, já que no universo formado pelas 26 indústrias pesquisadas foram identificadas 19 atividades distintas: construção civil, têxtil e de vestuário, tubos de PVC, produtos cirúrgicos, empresas de comunicação, distribuição de eletricidade, embalagens, estruturas metálicas etc. 


\subsubsection{Informações Acerca da Utilização do B2B nas Atividades de Suprimento Externo}

É patente a necessidade, por parte das empresas, de tornar a comunicação entre elas e seus fornecedores o mais ágil e eficiente possível. Esta imposição é fruto da crescente competitividade observada em todos os setores da economia. Neste sentido, vários procedimentos podem ser implementados com o objetivo de conferir mais rapidez, confiabilidade e menor custo às operações de suprimentos.

E, como já dito, uma das ferramentas que mais tem se destacado na busca pela otimização do sistema de suprimento externo é o moderno conceito de relacionamento entre empresas denominado Businessto-Business.

Com o objetivo de obter informações acerca da utilização do B2B nas atividades de suprimento externo nas indústrias campinenses, vários questionamentos foram feitos sobre o tema em questão.

A Figura 5 ilustra as diversas aplicações do B2B nas empresas pesquisadas. O mesmo revela os percentuais de utilização do $\mathrm{B} 2 \mathrm{~B}$ em relação a diversos aspectos pertinentes à área de suprimentos. De sua leitura, observa-se que o emprego da pesquisa de preços de insumos via Internet etc. (item "B" do gráfico) é aquele que apresenta maior índice de respostas "SIM" (26,9\%).

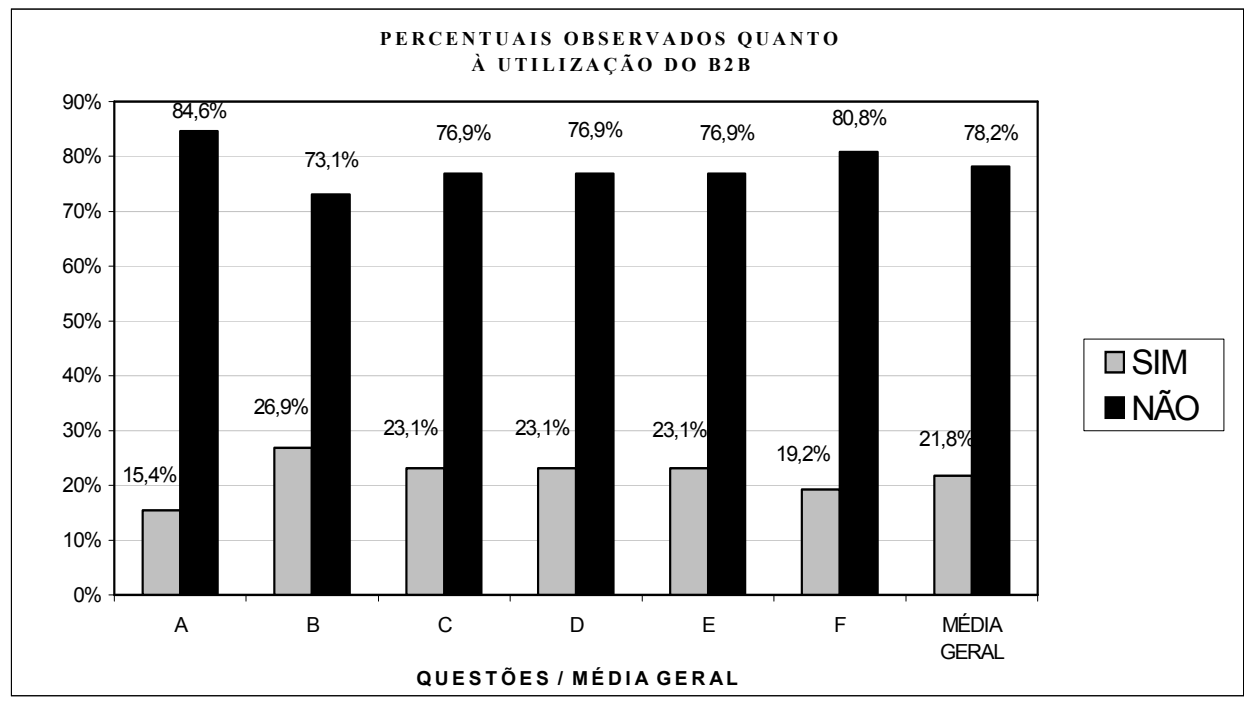

Figura 5 - Informações acerca da utilização do B2B nas atividades de Suprimento Externo - Fev/2002

\section{LEGENDA}

A - Sua empresa faz a programação de insumos (materiais) em conjunto com fornecedores por meios on-line? Especifique, se for o caso.

$\mathrm{B}$ - Há pesquisa de preços de insumos via Internet etc.?

$\mathrm{C}$ - Há ordens de compra ou pedidos de materiais feitos por meios eletrônicos?

$\mathrm{D}$ - O processo de acompanhamento das entregas (follow-up) é auxiliado por meios eletrônicos?

E - A sua empresa desenvolve algum projeto de produto com algum fornecedor (ou fornecedores)?

F - Há troca de informações da produção com algum fornecedor por meios eletrônicos?

MÉDIA GERAL - Média de respostas "SIM" e "NÃO" às questões "A", "B", "C", "D", "E" e "F".

FONTE: DADOS DA PESQUISA

Neste sentido, buscou-se verificar se o citado percentual (item "B" do gráfico - 26,9\%) é significativamente diferente da média geral assinalada na última coluna do referido gráfico (MÉDIA GERAL: "SIM" = 21,8\%). Essa preocupação deveu-se ao fato de que talvez esse aspecto pudesse merecer uma análise mais aprofundada, por apresentar o maior índice positivo entre todas as respostas coletadas. Caso, entretanto, não fosse verificada nenhuma diferença significativa deste aspecto com relação à média geral, poder-se-ia afirmar que se este item, em particular, não justificava o aprofundamento da pesquisa, muito menos justificavam os demais, que apresentaram percentuais ainda menores. Para essa constatação, empregou-se uma técnica estatística denominada teste de 
significância (Martins,2001), como forma de confirmar uma das seguintes hipóteses utilizadas no teste:

(1) Hipótese inicial $\left(H_{0}\right)$ : a proporção de respostas "SIM" referentes à questão B ("Há pesquisa de preços de insumos via Internet etc." ?) não é significativamente diferente da média geral.

Hipótese alternativa $\left(H_{1}\right)$ : a proporção de respostas "SIM" referentes à questão B ("Há pesquisa de preços de insumos via Internet etc." ?) é significativamente diferente da média geral.

(2) Nivel de significância $(\alpha)=1 \%$. Escolher a variável normal padronizada $(Z)$.

(3) Determinação da região de aceitação $(R A)$ e regiões críticas de rejeição $(R C)$ :

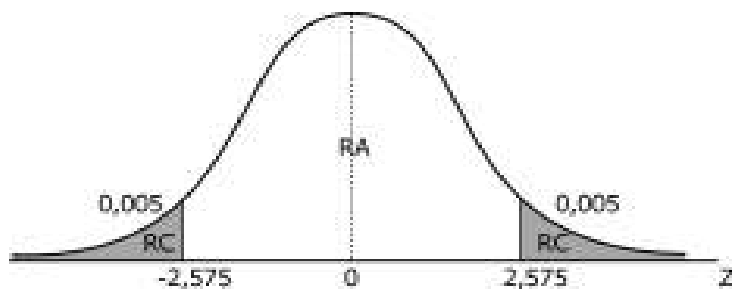

(4) Cálculo do valor da variável:

A Tabela de dados é

\begin{tabular}{c|c|c}
\hline RESPOSTAS \ÍNDICES & MÉDIA GERAL & QUESTÃO “B” \\
\hline RESPOSTAS “SIM” & $21,8 \%(5,6$ empresas $)$ & $26,9 \%(7$ empresas $)$ \\
\hline $\mathrm{N}^{\circ}$ DE RESPONDENTES & 26 & 26 \\
\hline
\end{tabular}

$\hat{p}=\frac{x_{1}+x_{2}}{n_{1}+n_{2}}=\frac{7+5,6}{26+26}=\frac{12,6}{52}=0,2423$

$Z_{c a l}=\frac{f_{1}-f_{2}}{\sqrt{\hat{p}(1-\hat{p})\left(\frac{1}{n_{1}}+\frac{1}{n_{2}}\right)}}=\frac{0,269-0,218}{\sqrt{0,2423 \times 0,7577 \times\left(\frac{2}{26}\right)}}=0,4292$

(5) Conclusão do teste:

Como $Z_{\text {cal }}=0,4292$ encontra-se na Região de Aceitação (RA), aceita-se $H_{0}$, concluindo, com risco de $1 \%$, que a proporção do conceito "SIM" para a questão " $B$ " é estatisticamente igual à proporção de conceito "SIM" para a média geral.

Para as demais questões ( $A, C, D, E$ e $F$ ) deduz-se que não há significativas variações (risco de $1 \%$ de erro) em relação à média geral, uma vez que todas elas apresentam proporções ainda menores de conceitos "SIM" que a questão $B$ e, portanto, suas respectivas análises resultariam em variações estatísticas ainda menores. Os resultados indicam, desta forma, que não há uma diferenciação significativa entre as respostas "SIM" de cada uma das questões quando comparadas, individualmente, com a média geral.

Como pode ser observado na Figura 5, diversas empresas afirmaram fazer uso de meios eletrônicos no trato com fornecedores e/ou clientes para atividades como obtenção de cotações de preços, troca de informações ou mesmo efetivação de pedidos de compras. Quando indagadas, entretanto, sobre quais seriam estes meios eletrônicos, as respostas se restringiram ao uso do correio eletrônico (e-mail). E nada mais. Naturalmente, o emprego de tais meios não é suficiente para que se possa afirmar que uma dada organização se utiliza do Business-to-Business em suas operações. O B2B se configura como uma verdadeira revolução, não apenas tecnológica, mas também cultural dentro da empresa. Trata-se de um conceito amplo que engloba fatores como efetivo estreitamento entre empresa e fornecedores, 
intensa troca de informações sobre a produção e sobre demandas futuras, planejamentos coordenados etc.

Apenas uma das organizações pesquisadas, pertencente ao grupo da empresas de médio porte, afirmou possuir um sistema efetivo de integração com fornecedores e clientes por meios eletrônicos. internet e extranet eram algumas das ferramentas utilizadas pela mesma para a efetivação e acompanhamento de pedidos, controle integrado de estoque etc. Entretanto, esta empresa não se mostrou receptiva à pesquisa e, sob a alegação de falta de interesse, se negou a abrir suas portas para um maior aprofundamento do presente estudo.

Os motivos alegados pelos responsáveis pelos setores de suprimentos para a não-implantação do B2B foram, basicamente, aqueles apontados no item 3.1. do presente artigo: alto custo, ausência de relacionamentos sólidos no supply chain, falta de interesse dos seus fornecedores nesta questão, falta de interesse por parte da cúpula da organização etc.

\section{Considerações Finais}

A pesquisa revelou que apesar de considerável parcela das organizações admitir poder obter ganhos com a utilização do B2B, tal empreitada apenas estava nos planos da organização a longo prazo (5 anos ou mais). Algumas outras, embora em menor número, demonstraram desconhecimento e/ou desinteresse nos procedimentos relacionados ao B2B e sequer consideravam a implantação do B2B como objetivo (mesmo que futuro). Na ótica destas últimas, tratava-se de algo demasiadamente caro, abstrato e dispensável.

Este panorama corrobora pesquisas realizadas em âmbito nacional que indicam que, verdadeiramente, os níveis de utilização do B2B ainda são baixos, em particular nas pequenas e médias empresas.

Naturalmente, isso não invalida a tendência de crescimento do setor do B2B. Tal fato pôde ser verificado pela intenção de grande parte das empresas em utilizar o B2B no futuro, tamanhas são as vantagens já comprovadas que a adoção do referido sistema pode trazer.

Por outro lado, ficou patente que a expansão do B2B realmente vai ocorrer de uma forma muito mais lenta e ordenada do que aquela anteriormente prevista pelos analistas e pelo próprio mercado.

\section{Referências}

ALBERTIN, Alberto Luiz. Comércio eletrônico: modelo, aspectos e contribuições de sua aplicação. $2^{\mathrm{a}}$ ed. São Paulo: Atlas, 2000.

ANDREOTTI, Orlando. Dicas para um e-commerce bem sucedido. Disponível em $<$ http://www.b2bmagazine.com.br>. Acesso em: 29 mai. 2003.

ARNOLD, J.R. Tony. Administração de materiais: uma introdução. São Paulo: Atlas, 1999.

CHAPINOTTE, Celso. E-business no setor industrial. Disponível em: $<$ http://www.investnews.net $>$. Acesso em: 13 mai. 2002.

D'ANGELO, Vanessa. Comércio eletrônico registra crescimento limitado. Gazeta Mercantil, 22, 23 e 24 mar.2002. p.C-2.

DAVIS, Mark M.; AQUILANO, Nicholas J., CHASE, Richard B. Fundamentos da administração da produção. $3^{\mathrm{a}}$ ed. Porto Alegre: Bookmam, 2001.

DIAS, Marco A. P. Administração de materiais: uma abordagem logística. 4.ed. São Paulo: Atlas, 1993. 399p. 
DIAS, Mário; COSTA, Roberto Figueiredo. Manual do comprador: conceitos, técnicas e práticas indispensáveis em um departamento de compras. São Paulo: Edicta, 2000.

FELIPINI, Dailton. A Internet na gestão de fornecedores. Disponível em $<\mathrm{http}$ ://www.ecommerce.org.br>. Acesso em: 30 mai. 2003.

FELLENSTEIN, Craig; WOOD, Ron. Exploring e-commerce, global e-business and e-societies. Upper Saddle River: Prentice-Hall, 1999.

HARDING, H. A. Administração da produção. São Paulo: Atlas, 1981. Cap. 11, p. 117-121: Administração de materiais.

ISATTO, Eduardo L.; FORMOSO, Carlos T. Compras. Revista Téchne. São Paulo, n. 28, p. 48-51. mai.jun. 1997.

KEESE, Rodrigo. Business-to-Business: A inclusão empresarial. Disponível em $<$ http:// www.b2bmagazine.com.br>. Acesso em: 29 maio 2003.

LIMA, Eduardo Jorge Lapa. Para onde caminha a tecnologia da informação... Disponível em $<$ http://www.informal.com.br $>$ Acesso em: 30 mai. 2003.

LUCENA, Fábio de Oliveira; SEVERIANO FILHO, Cosmo. Suprimento externo: uma abordagem técnica das práticas empresariais. João Pessoa: Editora Universitária da UFPb, 2002.

MALLMANN, Dorval Olívio. As relações de suprimento analisadas de acordo com a teoria dos jogos. In: ENCONTRO ANUAL DA ASSOCIAÇÃO NACIONAL DOS PROGRAMAS DE PÓSGRADUAÇÃO EM ADMINISTRAÇÃO, 19, 1995, João Pessoa. Anais... Rio de Janeiro: ANPAD, 1995. v.1. p.83-95.

MARTINS, Gilberto de Andrade. Estatística geral e aplicada. São Paulo: Atlas, 2001.

MCGEE, James, PRUSAK, Laurence. Gerenciamento estratégico da informação: aumente a competitividade e a eficiência de sua empresa utilizando a informação como uma ferramenta estratégica. Rio de Janeiro: Campus, 1994.

MERLI, Giorgio. Comakership; a nova estratégia para os suprimentos. Rio de Janeiro: Qualitymark, 1994.

PERSONA, Mário. Peça de museu. Disponível em: <http://www.widesoft.com.br $>$. Acesso em: 31 jan. 2000 .

REIS, Dayr A. dos. Administração da produção: sistemas, planejamento e controle. São Paulo: Atlas, 1978. 326p. Cap. 8, p.195-243: Decisões sobre o fluxo de materiais.

ROMITI, Marcos. O real espaço do e-commerce. Disponível em: <http://www.investnews.net>. Acesso em: 24 abr. 2002.

SLACK, Nigel et al. Administração da produção. São Paulo: Atlas, 1997. 